DOI: https://doi.org/10.47405/mjssh.v6i11.1171

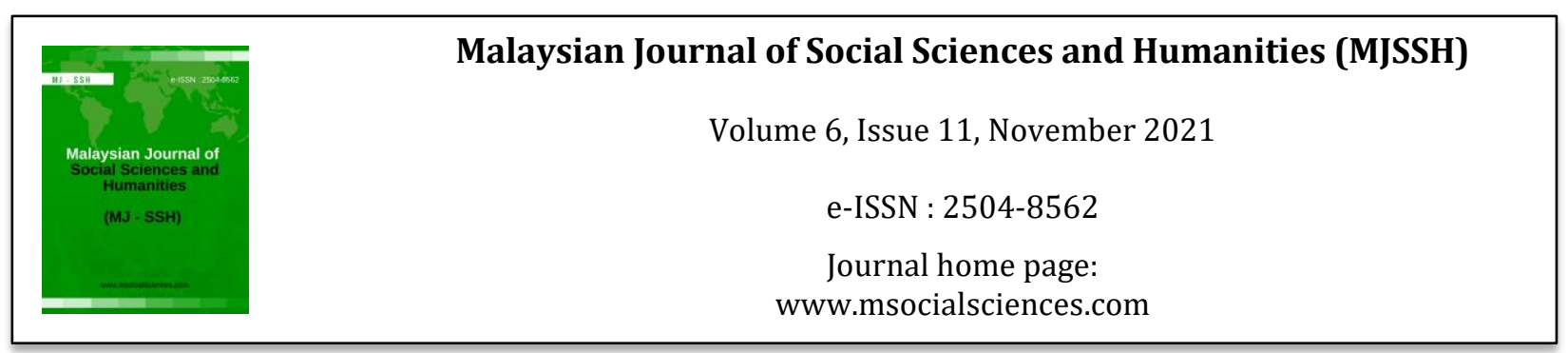

\title{
Penggunaan Buku Nombor dalam Pengajaran Awal Matematik Kanak-Kanak Prasekolah
}

\author{
Connie Shin @ Connie Cassy Ompok ${ }^{1}$, Jusiah Idang ${ }^{1}$, Musirin Mosin ${ }^{1}$, Alley Emison${ }^{1}$, \\ Priscilla Kyle Payne ${ }^{2}$ \\ 1Fakulti Psikologi dan Pendidikan, Universiti Malaysia Sabah (UMS), Malaysia \\ ${ }^{2}$ Fakulti Sains dan Sumber Alam, Universiti Malaysia Sabah (UMS), Malaysia \\ Correspondence: Connie Shin @ Connie Cassy Ompok (connieompok@ums.edu.my)
}

\begin{abstract}
Abstrak
Menyediakan kanak-kanak untuk pendidikan awal Matematik mendapat banyak perhatian dalam bidang pendidikan awal kanak-kanak. Perkembangan awal Matematik dan kemahiran literasi awal adalah saling berhubung kait. Buku nombor boleh membantu kanak-kanak memahami konsep dan memperkukuhkan lagi pengetahuan dan kemahiran awal Matematik. Artikel ini membincangkan tentang peranan buku nombor dalam membantu kanak-kanak belajar Matematik.
\end{abstract}

Kata kunci: buku nombor, awal matematik, kanak-kanak prasekolah

\section{The Use of Number Books in Teaching Children Early Mathematics}

\begin{abstract}
Preparing young children for Mathematics education is garnering much attention in the field of early childhood education. The development of early math and early literacy skills are intertwined. Number book can help children developing knowledge and skills of Mathematics. This article discusses the role of number books in helping pre-schoolers learn math.
\end{abstract}

Keywords: number books, early mathematics, preschool children

\section{Pengenalan}

Pengiktirafan para pendidik tentang literasi dalam pengajaran dan pembelajaran mata pelajaran Matematik sebagai kaedah yang boleh digunakan semakin meningkat. Terdapat kajian-kajian lepas yang menggunakan istilah seperti buku nombor, buku bergambar dan sastera kanak-kanak dalam merujuk kepada kaedah yang menggabungjalinkan Tunjang Bahasa dan Komunikasi dengan Matematik dalam Tunjang Sains dan Teknologi. Dalam kajian ini, penyelidik menggunakan istilah buku nombor seperti yang digunakan dalam kajian Young-Loveridge (2004) yang mendapati bahawa penggunaan permainan dan buku nombor memberikan kesan yang signifikan terhadap pencapaian awal Matematik. 


\section{Penggunaan Buku Nombor Dalam Pengajaran Awal Matematik Kanak-Kanak}

Menurut Skoumpourdi dan Mpakopoulou (2011), buku kanak-kanak yang berkisar tentang Matematik boleh menjadi alat untuk menjadikan mata pelajaran Matematik bermakna melalui perbincangan dan komunikasi tentang idea-idea Matematik. Pandangan ini disokong oleh beberapa tokoh yang menyatakan tentang kegunaan buku-buku cerita tentang Matematik. Antaranya ialah Haven (2000) yang menyatakan bahawa buku kanak-kanak menyediakan imej di minda pendengar. Bagi Griffiths dan Clyne (1991) pula, buku bergambar secara implisit dan eksplisit boleh membantu kanak-kanak mengembangkan konsep, menyelesaikan masalah dan membuat perkaitan yang menyumbang kepada perkembangan sikap positif terhadap Matematik.

Penyelidik lepas seperti Casey, Kersh dan Young (2004), Shih dan Giorgis (2004), Egan (1989) dan, Skoumpourdi dan Mpakopoulou (2011) berpendirian bahawa buku kanak-kanak mengandungi unsur cerita yang memberi manfaat kepada kanak-kanak. Skoumpourdi dan Mpakopoulou (2011) menyifatkan cerita boleh memperkenalkan dan menerangkan tentang konsep Matematik yang boleh diingati. Casey et al. (2004) pula melihat penceritaan adalah perantara yang efektif dalam pengajaran mata pelajaran Matematik untuk kanak-kanak.

Menurut Shih dan Giorgis (2004), terdapat tiga jenis literatur yang menggabungjalinkan konsep Matematik kepada cerita. Pertama, asas cerita adalah Matematik. Kedua, cerita difahami sekiranya Matematik difahami. Ketiga, Matematik mungkin muncul secara semula jadi.

Tidak terdapat kekurangan sorotan kajian yang menyentuh tentang literasi tentang Matematik dalam kehidupan seseorang. Mengikut Shatzer (2008), literasi tentang Matematik membantu kanak-kanak melihat Matematik sebagai sebahagian daripada kehidupan, menghargai Matematik dengan membina keyakinan tentang kebolehan Matematik di samping membantu menyelesaikan masalah melalui penaakulan. Van den Heuvel-Panhuizen dan Van den Boogaard (2008) melihat penggunaan buku bergambar sebagai memberi motivasi kepada murid, menyatukan Matematik dengan perasaan dan menyemai minat. Bagi Zazkis dan Liljedahl (2009), penggunaan literasi tentang Matematik menyokong daya ingatan, motivasi, penglibatan dan penambahbaikan kemahiran analitikal di samping menarik minat kanak-kanak, mengurangkan ketakutan, menyediakan persekitaran yang selesa dan menyokong hubungan antara pendidik dan murid.

Kanak-kanak pada awal usia memerlukan buku yang mengandungi gambar bagi membantu mereka memahami dengan mudah berbanding dengan buku yang hanya mempunyai perkataan. Dalam erti kata yang lain, kanak-kanak memerlukan maklumat visual untuk membantu mereka memahami teks. Dalam kajian yang dijalankan oleh Preissler dan Carey (2004), mereka mendapati bahawa kanakkanak seawal 18 bulan sudah memahami simbol gambar dengan objek sebenar. Dalam kajian yang lain, Skoumpourdi dan Mpakopoulou (2011) menggunakan buku bergambar sebagai pencetus kepada pemikiran Matematik kanak-kanak tadika dalam pengajaran geometri. Kajian mereka adalah untuk menentukan sama ada kanak-kanak dapat mengenal objek sebenar dari ilustrasi gambar yang tidak jelas melalui buku bergambar dan adakah kanak-kanak dapat mengaitkannya dengan objek-objek di persekitaran mereka. Dapatan kajian mereka menunjukkan bahawa buku bergambar memudahkan dan menggalakkan apabila kanak-kanak dapat menamakan bentuk-bentuk mudah daripada objek persekitaran.

Selain dapatan kajian Preissler dan Carey (2004), dan Skoumpourdi dan Mpakopoulou (2011), beberapa kajian lain juga menunjukkan bahawa literasi yang mempunyai gambar memberikan banyak manfaat kepada kehidupan kanak-kanak. Kajian Van den Heuvel-Panhuizen dan Van den Boogaard (2008) misalnya, mereka mengenal pasti bukti perkembangan kognitif semasa menggunakan buku bergambar. Gaya bahasa kanak-kanak yang berbeza semasa melihat gambar tentang kejadian-kejadian dalam cerita berbanding dengan halaman buku yang hanya mengandungi judul buku merupakan bukti adanya perkembangan kognitif. Selain itu, kajian Elia, Van den Heuvel-Panhuizen dan Georgiou (2010) juga menunjukkan kepentingan gambar itu sendiri sebagai pemberi maklumat dan dengan sendirinya meningkatkan kognitif kanak-kanak. Gambar sebagai strategi dalam pengajaran dan pembelajaran yang bersesuaian kerana kanak-kanak boleh belajar tentang perkataan sekaligus 
berupaya membuat generalisasi. Dalam pendidikan Matematik, gambar digunakan oleh kanak-kanak untuk menyokong penyelesaian masalah seperti penambahan dan penolakan yang menggunakan simbol Matematik (Linder et al., 2011). Ringkasnya, buku nombor yang mempunyai teks atau cerita mudah dan gambar adalah penting dalam membantu perkembangan kognitif kanak-kanak. Kanakkanak akan berimaginasi semasa karakter penyampaian cerita menyatakan masalah Matematik (Casey, 2004). Oleh itu, ilustrasi yang ringkas dan realistik perlu mengambil kira minat kanak-kanak (Shih \& Giorgis, 2004; House \& Rule, 2005; Skoumpourdi \& Mpakopoulou, 2011).

Semasa membaca buku bergambar, tingkah laku ibu bapa seperti menunjuk, melabel dan memberi komen pada gambar atau bertanya soalan tentang gambar atau cerita adalah berkaitan dengan pembelajaran bahasa kanak-kanak (Cronan, Cruz, Arriaga \& Sarkin, 1996; Arnold, Lonigan, Whitehurst \& Epstein, 1994). Sebaliknya, kajian yang dijalankan oleh Greenhoot dan Semb (2008) mendapati bahawa gambar sahaja tidak membantu kanak-kanak melahirkan idea. Jika hanya menggunakan skrip, penaakulan dan penyelesaian masalah Matematik mungkin terhalang (Parks \& Bridges-Rhoads, 2012). Gambar dan teks berperanan dalam memperkenalkan masalah Matematik.

Penggunaan buku cerita dan buku bergambar dalam memberikan nilai yang bermakna dalam pengajaran dan pembelajaran mata pelajaran Matematik tidak dapat dipertikaikan lagi (Anderson, Anderson \& Shapiro, 2004; Casey, Erkut, Ceder \& Young 2008; Van den Heuvel-Panhuizen \& Van den Boogaard 2008; Elia et al., 2010) kerana buku bergambar dianggap sebagai pencetus kepada pemikiran Matematik kanak-kanak (Van den Heuvel-Panhuizen, Van den Boogard \& Doig, 2009; Skoumpourdi \& Mpakopoulou, 2011). Ini bermakna penggunaan buku kanak-kanak boleh dijadikan kaedah mengajar yang efektif dalam pengajaran Matematik untuk kanak-kanak prasekolah.

Pemilihan, penyampaian dan penutup cerita adalah penting. Menurut Zazkis dan Liljedahl (2009), cerita boleh dibezakan melalui kandungan cerita Matematik. Antara jenis cerita ialah cerita yang menyediakan kerangka, cerita-cerita yang menghiburkan, cerita yang digabungjalinkan, cerita yang memperkenalkan, cerita yang menerangkan, cerita yang bertanya soalan dan juga cerita tentang jenaka.

Dari segi penyampaian cerita, Egan (1989) menekankan cara cerita disampaikan perlu mengenal pasti penglibatan murid untuk membantu mereka memperoleh makna daripada cerita yang disampaikan. Zazkis dan Liljedahl (2009) memberikan tiga pendapat tentang cara cerita dipersembahkan. Pertama, merangka aktiviti yang menghubungkan masalah sebenar. Kedua, meminta murid untuk menulis kesimpulan atau penyambung cerita. Ketiga, memperkenalkan masalah yang berlainan tetapi berkaitan, atau untuk menulis bab yang seterusnya. Mengikut Casey et al. (2004), cerita perlu disampaikan secara berperenggan untuk membantu kanak-kanak memperoleh pengetahuan Matematik. Egan (1989), Zazkis dan Liljedahl (2009) dan Casey et al. (2004) menegaskan bahawa cerita perlu disampaikan dalam keadaan menarik dan penutup yang meningkatkan kognitif kanak-kanak.

Setelah meneliti kajian-kajian terdahulu, penyelidik mendapati bahawa penulisan tentang buku bergambar memfokuskan kepada cerita dan ilustrasi gambar. Van den Heuvel-Panhuizen, Van den Boogard dan Doig (2009) berkeyakinan bahawa guru perlulah menggunakan buku besar sebagai satu kaedah mengajar yang berpotensi untuk membantu kanak-kanak belajar. Guru perlu berhati-hati ketika memilih buku kerana buku yang terlalu banyak adalah tidak sesuai dan berkemungkinan buku-buku tersebut tidak dibacakan kepada kanak-kanak (Manning \& Kirkland, 2012). Sperling dan Head (2002) mencadangkan supaya guru-guru membacakan buku setiap hari iaitu lima kali seminggu kepada kanak-kanak. Namun mereka mendapati bahawa tidak ada seorang guru pun yang berbuat demikian.

Kajian lepas penting dijadikan asas dalam pembangunan buku nombor di peringkat prasekolah. Semakin hari semakin banyak maklumat yang diperoleh dengan menjadikan kajian lepas sebagai rujukan dalam membina buku nombor yang bersesuaian dengan KSPK. Literasi yang menghubungkan pendidikan Matematik masih kurang di Malaysia. Oleh itu, penyelidik telah mengambil inisiatif dengan mencari buku-buku nombor yang menceritakan tentang Matematik dengan bantuan teknologi maklumat dari berbagai sumber di serata dunia. Antaranya ialah buku yang bertajuk Five Little Sharks Swimming in the Sea oleh Metzger (2005) untuk membantu kanak-kanak belajar tentang nombor dan 
bilangan, Animals on Board oleh Murphy (1998) untuk membantu kanak-kanak belajar tentang memberi contoh masalah penambahan melalui ayat Matematik, Chicka-chicka 123 oleh Martin, Sampson dan Ehlert (2004) yang membantu kanak-kanak menyebut angka, membuat perbandingan nombor dan banyak lagi buku nombor yang ditulis untuk pendidikan awal Matematik kanak-kanak. Kajian berkaitan pengajaran menggunakan permainan telah banyak dijalankan oleh penyelidik seperti Ompok et al. (2020), Ompok dan Bacotang (2019), Ling, Pang dan Ompok (2018), Ompok et al. (2021), Ompok, Doig dan Tambagas (2019), Ompok (2021), Ompok (2015) serta Doig dan Ompok (2010). Walau bagaimanapun, baru satu kajian yang dijalankan dalam negara menggunakan buku nombor seperti kajian Ompok et al. (2018).

Setelah membincangkan tentang kepentingan bagaimana kanak-kanak belajar, mungkin penting untuk melihat bagaimanakah idea Piaget sesuai untuk kaedah buku nombor. Piaget (1962) menyatakan bahawa operasi yang berlaku mesti berasaskan kepada tiga fenomena mental yang penting iaitu pengamatan, ingatan dan bayangan. Pengamatan merupakan suatu proses yang melibatkan kanakkanak untuk memberikan sepenuh perhatian terhadap sesuatu yang dilihat. Ingatan ialah satu proses pembinaan, pengumpulan dan mengingat kembali memori tentang peristiwa yang lalu. Kejadian yang berlaku memberi bayangan. Piaget menjelaskan bahawa penerimaan maklumat bergantung pada pemprosesan, penterjemahan data sensori, menukar data ke dalam bentuk yang boleh disimpan dan diguna semula apabila diperlukan. Jelasnya, kepentingan fenomena ini banyak dilihat melalui kaedah buku nombor. Bahan pembelajaran menggunakan cerita menyebabkan pengekalan yang lebih baik dan membantu mengingat semula cerita (Mishra, 2003).

Rajah 1: Buku Nombor

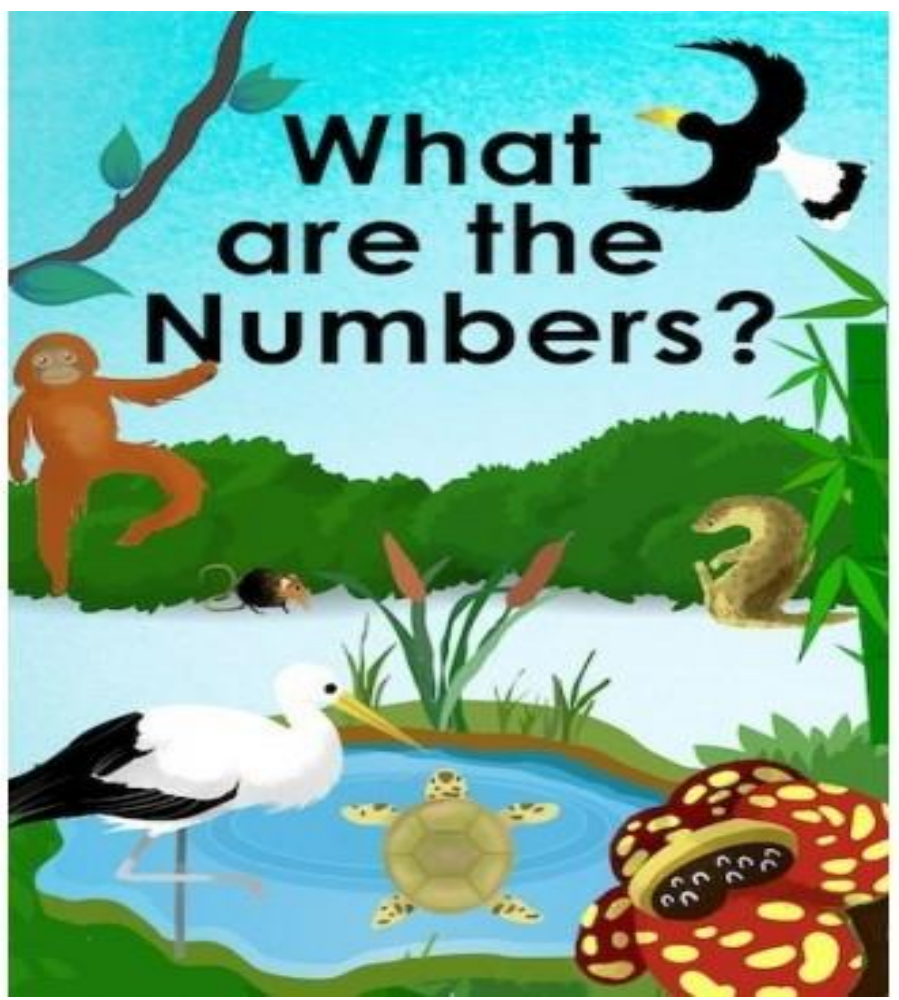

Buku nombor What are the Numbers (Ompok, Ling, Pang dan Ho, 2018) direka khas ini adalah untuk mengajar kanak-kanak prasekolah mengenal dan menulis nombor 1 hingga 20. Penulis telah menggunakan imej flora dan fauna Borneo dalam membantu kanak-kanak mengenal nombor. Terdapat nombor yang tersembunyi dalam gambar ini bertujuan untuk mencetuskan 4C iaitu pemikiran kritikal (mengenal pasti nombor yang terdapat dalam gambar), kreativiti (lebih dari satu nombor pada satu imej), komunikasi dan kemahiran kolaborasi (critical thinking, creativity, communication and collaboration skills) dalam kalangan kanak-kanak. 


\section{Rajah 2: Buku Kira Bersama Lala}
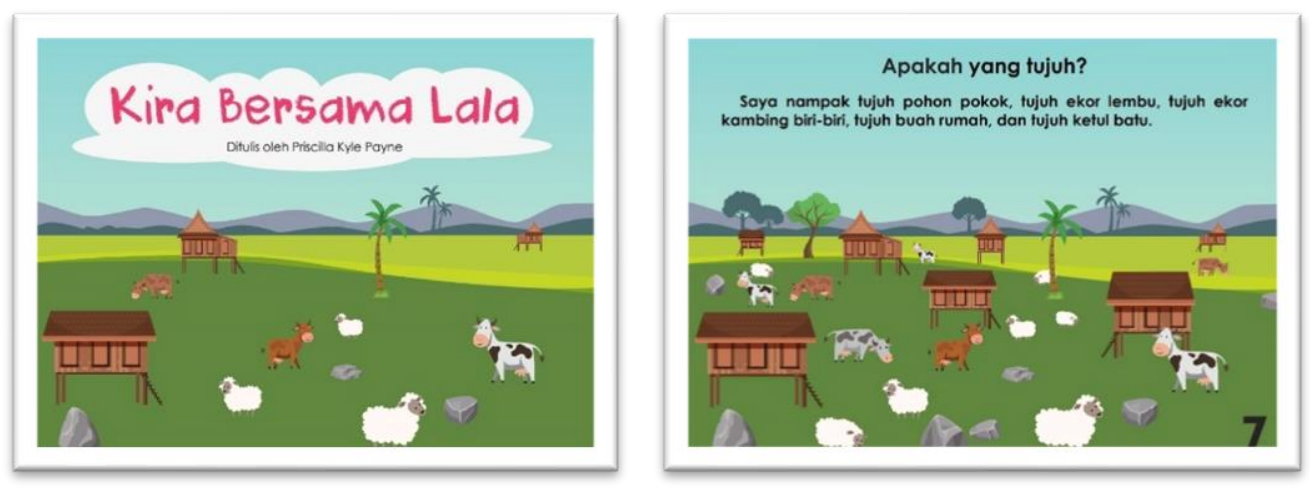

Gambar di atas menunjukkan Buku Kira Bersama Lala yang ditulis oleh Priscilla Kyle Payne pada tahun 2021.

Rajah 3: Buku Kira Bersama Lala

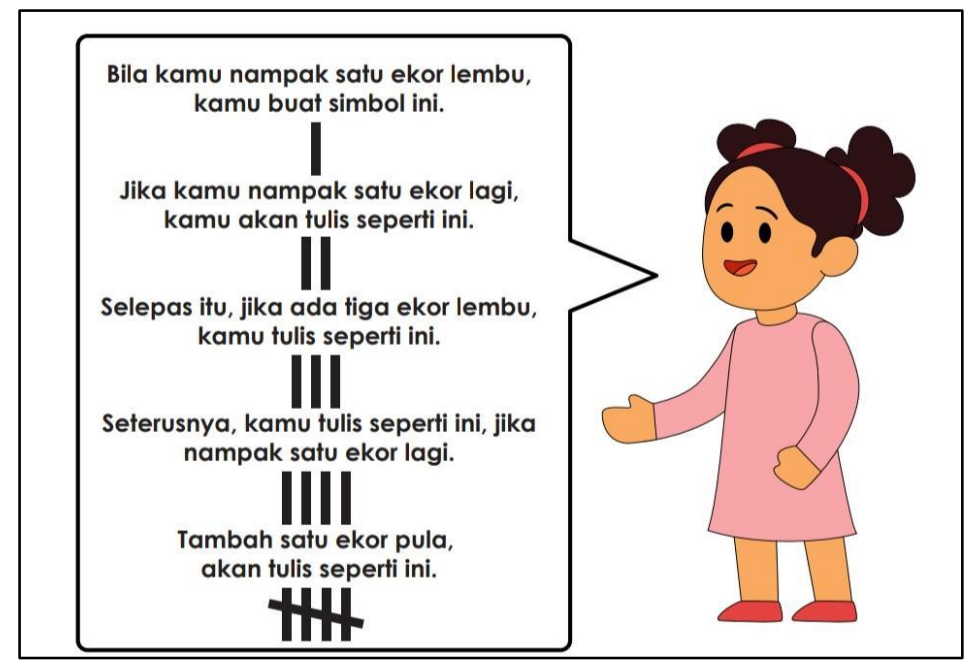

Buku ini membantu kanak-kanak memahami nombor dan mengunakan set representasi bertulis (menulis simbol untuk menunjukkan jumlah yang dikira). Helaian di bawah menunjukkan kanakkanak akan memahami bahawa setiap imej mempunyai bilangan yang sama pada muka surat yang sama.

Rajah 4: Menulis Simbol Untuk Menunjukkan Jumlah Yang Dikira

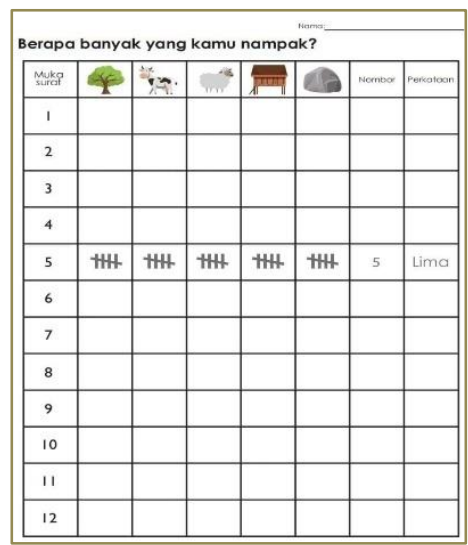




\section{Kesimpulan}

Pendidik kanak-kanak haruslah mengembangkan lagi amalan pedagogi yang berkesan dalam menyediakan kanak-kanak dengan pengalaman awal Matematik yang lebih baik. Terdapat keperluan untuk menghasilkan buku nombor untuk membantu kanak-kanak di Malaysia belajar Awal Matematik.

\section{Rujukan}

Anderson, A., Anderson, J., \& Shapiro, J. (2004). Mathematical discourse in shared storybook reading. Journal for Research in Mathematics Education, 35(1):5-33.

Arnold, D. H., Lonigan, C. J., Whitehurst, G. J., \& Epstein, J. N. (1994). Accelerating language development through picture book reading: Replication and extension to a videotape training format. Journal of Educational Psychology, 86(2):235-243.

Casey, B. (2004). Mathematics problem-solving adventures: A language-arts-based supplementary series for early childhood that focuses on spatial sense. In Clements, D., \& Samara, J. (eds.). Engaging young children in Mathematics: Standards for early childhood Mathematics education, pp. 377-389. Mahwah: Lawrence Erlbaum.

Casey, B. M., Kersh, J. E., \& Young, J. M. (2004). Storytelling sagas: An effective medium for teaching early childhood Mathematics. Early Childhood Research Quarterly, 19, 167-172.

Casey, B. M., Erkut, S., Ceder, I., \& Young, J. M. (2008). Use of a storytelling context to improve girl's and boy's geometry skills in kindergarten. Journal of Applied Developmental Psychology, 29, 29-48.

Cronan, T. A., Cruz, S. G., Arriaga, R. I., \& Sarkin, A. J. (1996). The effects of a community-based literacy program on young children's language and conceptual development. American Journal of Community Psychology, 24(2), 251-272.

Doig, B., Van den Heuvel-Panhuizen, M., \& Groves, S. (2009). Young children's Mathematical development. Melbourne: Deakin University and University of Utrecht.

Doig, B., \& Ompok, C. (2010). Assessing young children's Mathematical abilities through games. Procedia-Social and Behavioral Sciences, 8, 228-235.

Egan, K. (1989). Teaching as storytelling: An alternative approach to teaching and curriculum in the elementary school. Chicago: The University of Chicago Press.

Elia, I., Van den Heuvel-Panhuizen, M., \& Georgiou, A. (2010). The role of pictures in picture books on children's cognitive engagement with Mathematics. European Early Childhood Education Research Journal, 18(3):125-147.

Greenhoot, A. F., \& Semb, P. A. (2008). Do illustrations enhance preschooler's memories for stories? Age-related change in the picture facilitation effect. Journal of Experimental Child Psychology, 99, 271-287.

Griffiths, R., \& Clyne, M. (1991). Once upon a time... Australian Mathematics Teacher, 47(1):10-13.

Haven, K. (2000). Super simple storytelling: A can-do guide for every classroom, every day. Englewood: Teacher Ideas Press.

House, C. A., \& Rule, A. C. (2005). Preschooler's ideas of what makes a picture book illustration beautiful. Early Childhood Education Journal, 32(5), 283-290.

Kementerian Pendidikan Malaysia. (2017). Kurikulum Standard Prasekolah Kebangsaan. Kuala Lumpur: Bahagian Pembangunan Kurikulum.

Linder, S. M., Powers-Costello, B., \& Stegelin, D. A. (2011). Mathematics in early childhood: Research-based rationale and practical strategies. Early Childhood Education Journal, 39, 29-37.

Ling MT., Pang V., \& Ompok C. S. (2018) Measuring Change in Early Mathematics Ability of Children Who Learn Using Games: Stacked Analysis in Rasch Measurement. In: Zhang $Q$. (eds) Pacific Rim Objective Measurement Symposium (PROMS) 2016 Conference Proceedings. Springer, Singapore. https://doi.org/10.1007/978-981-10-8138-5_17.

Manning, M., \& Kirkland, L. (2012). Books for children: Books that delight preschoolers. Childhood Education, 88(6), 400-403.

Martin, B. J., Sampson, M., \& Ehlert, L. (2004). Chicka Chicka 1, 2, 3. Broadway: Scholastic.

Metzger, S. (2005). Five little sharks swimming in the sea. Broadway: Scholastic.

Murphy, S. J. (1998). Animals on Board. New York: HarperCollins Publishers. 
Mishra, A. (2003). Age and school related differences in recall of verbal items in a story context. Social Science International, 19, 12-18

Piaget, J. (1962). Play, dreams and imitation in childhood. New York: W.W. Norton.

Ompok, C. S., \& Bacotang, J. (2019). Kesan kaedah mengajar terhadap pencapaian awal matematik dalam kalangan kanak-kanak prasekolah. Jurnal Pendidikan Awal Kanak-Kanak Kebangsaan, 8, 8-16. https://doi.org/10.37134/jpak.vol8.2.2019.

Ompok, C. S., Pang, V., \& Ho, C. M. (2013). Pembinaan Instrumen Pencapaian Awal Matematik untuk Kanak-kanak Prasekolah [Instrumen development of early maths performance for preschool children]. Paper presented at the Proceeding of the 2011 International Early Childhood Conference, Terengganu, Malaysia.

Ompok, C. S., Mei Teng, L., \& Sapirai, J. (2021). Effect of games towards children's mathematics performance. Southeast Asia Early Childhood Journal, 10(1), 1-17. https://doi.org/10.37134/saecj.vol10.1.1.2021.

Ompok, C. S., Teng, L., Pang, V., Mun, H., Abdullah, A., \& Sapirai, J. (2018). Early mathematics learning in reading and writing numerals: Learning through "What are the numbers?" A picture book made up of Flora and Fauna in Borneo. Southeast Asia Early Childhood Journal, 7, 52-59. https://doi.org/10.37134/saecj.vol7.6.2018.

Ompok, C. S., Doig, B., \& Tambagas, M. (2018). Patterns of Young Children's Number Sense Development as Assessed by How Many Hidden Game. Journal of Cognitive Sciences and Human Development, 4(2), 12-17. https://doi.org/10.33736/jcshd.1117.2018.

Ompok, C. S., Ling, M. T., Abdullah, S. N. M. @ S., Tambagas, M., Tony, E. E., \& Said, N. (2020). Mentor-mentee programme for STEM education at preschool level. Southeast Asia Early Childhood Journal, 9(1), 1-14. Retrieved from https://ejournal.upsi.edu.my/index.php/SAECJ/article/view/3147

Ompok, C. S. (2021). Penggunaan Kaedah Permainan, Buku Nombor dan Lembaran kerja dalam pembelajaran Matematik Awal kanak-kanak. Malaysian Journal of Social Sciences and Humanities (MJSSH), 6(10), pp. 235 - 251. doi: https://doi.org/10.47405/mjssh.v6i10.1117.

Ompok, C. S. (2021). Pencapaian Awal Matematik Kanak-kanak mengikut Tempoh Berada di Prasekolah dan Jantina. Malaysian Journal of Social Sciences and Humanities (MJSSH), 6(10), pp. 217 - 225. doi: https://doi.org/10.47405/mjssh.v6i10.1116.

Ompok, C. S. (2015). Kesan penggunaan kaedah permainan, buku nombor dan lembaran kerja terhadap pencapaian awal Matematik dalam kalangan kanak-kanak prasekolah kebangsaan. Thesis Doktor Ijazah Falsafah UMS. https://scholar.google.com/citations?view_op=view_citation\&hl=en\&user=B5XCKF4AAAAJ\&c itation_for_view=B5XCKF4AAAAJ:3fE2CSJIr18C

Ompok, C. S., Ling, M. T., Abdullah, S. N. M. @ S., Tambagas, M., Tony, E. E., \& Said, N. (2020). Mentor-mentee programme for STEM education at preschool level. Southeast Asia Early Childhood Journal, 9(1), 1-14.

Ompok, C. S., Ling, M.T., Pang, V., \& Ho, C.M. (2018). What are the numbers. Oyez! Books for Children.

Parks, A. N., \& Bridges-Rhoads, S. (2012). Overly scripted: Exploring the impact of a scripted literacy curriculum on a preschool teacher's instructional practices in Mathematics. Journal of Research in Childhood Education, 26, 308-324.

Preissler, M. A., \& Carey, S. (2004). Do both pictures and words function as symbols for 18 and 24 month old children? Journal of Cognition and Development, 5(2),185-212.

Shatzer, J. (2008). Picture book power: Connecting children's literature and Mathematics. International Reading Association, 61(8), 649-653.

Shih, J., \& Giorgis, C. (2004). Building the Mathematics and literature connection through children's responses. Teaching Children Mathematics, 10(6), 328-333.

Skoumpourdi, C. and Mpakopoulou, I. 2011. The prints: A picture book for pre-formal geometry. Early childhood Education Journal, 39, 197-206.

Sperling, R. A., \& Head, D. M. (2002). Reading attitudes and literacy skills in prekindergarten children. Early Childhood Education, 29(4), 233-236.

Van den Heuvel-Panhuizen, M., \& Van den Boogaard, S. (2008). Picture books as an impetus for kindergarten's Mathematical thinking. Mathematical Thinking and Learning, 10(4), 341-373. 
DOI: https://doi.org/10.47405/mjssh.v6i11.1171

Van den Heuvel-Panhuizen, M., Van den Boogaard, S., \& Doig, B. (2009). Picture books stimulate the learning of Mathematics. Australia Journal of Early Childhood, 34(3), 30-39.

Young-Loveridge, J. M. (2004). Effects on early numeracy of a program using number books and games. Early Childhood Research Quarterly, 19, 82-98.

Zazkis, R., \& Liljedahl, P. (2009). Teaching Mathematics as storytelling. Netherlands: Sense Publishers. 